\title{
Un documento literario poco convencional: la inscripción de Mnesíepes (fragmento $\left.\mathrm{E}_{1} \mathrm{II}\right)^{*}$
}

\author{
Violeta Gomis García \\ Universidad Autónoma de Madrid \\ violeta.gomis@uam.es
}

An unusual literary document: the Mnesiepes Inscription (fragment $\mathrm{E}_{1} \mathrm{II}$ )

La inscripción de Mnesíepes es un documento epigráfico bien conocido en los estudios sobre la tradición arquiloquea, pero parece oportuno analizar esta inscripción en sí misma, por separado, ya que se trata de un texto literario complejo, escrito por alguien culto, en un tiempo y un espacio determinados y con el fin de desempeñar una función muy concreta en el periodo helenístico de Paros. El texto de esta inscripción ofrece información sobre Arquíloco y la importancia que adquirió después de su muerte, pero también, sobre el contexto social, cultural y religioso de la isla en el s. III a.C.

Palabras clave: Mnesíepes; Arquíloco; epigrafía griega; inscripción literaria; cuento popular.
The Mnesiepes inscription is a well known epigraphical document in studies of Archilocheian tradition. However it is time to examine this inscription itself, separately, because it is a complex literary text written by somebody cultured, at a particular time, in a specific space, in order to perform a very special function in hellenistic Paros. The text of this inscription provides information about Archilochus and his importance after his death, but also about the social, cultural and religious condition of the island in the $3 \mathrm{rd}$ century B.C.

Key words: Mnesiepes; Archilochus; greek epigraphy; literary inscription; folktale.

\section{LA INSCRIPCIÓN DE MNESÍEPES}

La piedra también se utilizó en el mundo griego como vehículo transmisor de textos literarios, en su mayoría fragmentos o versos sueltos de

* Este estudio se encuadra dentro del proyecto de investigación FFI2012-35721-C02-01 y parte del TFM La leyenda de Arquíloco de Paros, estudio de las inscripciones de Sóstenes y Mnesíepes (sep. 2011, UAM), realizado bajo la dirección de la profesora Araceli Striano, a quien agradezco sinceramente su confianza, apoyo y dedicación constantes. Doy las gracias también a los autores anónimos de los informes elaborados para la revista, que, con sus aportaciones, sin duda han contribuido a mejorar este trabajo. 
composiciones épicas, líricas o filosóficas. No obstante, muchas de las inscripciones que conservamos hoy en día son textos literarios en sí mismos que gozaron de gran popularidad en los ámbitos más cotidianos de la sociedad al estar expuestas de forma pública y al alcance de un mayor grupo de población; es el caso de las inscripciones métricas (epigramas funerarios, inscripciones votivas, etc.), aunque se ha considerado que este tipo de textos, en su mayoría, tienen un valor literario secundario y no aportan datos relevantes por su carácter ordinario y a la vez, local, por lo que no han sido objeto de análisis literarios exhaustivos. Es cierto que estos textos suelen estar escritos en verso, pero eventualmente se pueden encontrar inscripciones literarias en prosa que, a excepción de algunos trabajos recientes ${ }^{1}$, tampoco se han estudiado suficientemente desde esta perspectiva $\mathrm{y}$, según creemos, son también textos literarios igualmente importantes y valiosos para comprender mejor la historia cultural y literaria del mundo griego antiguo. Por tanto, el objetivo fundamental de este trabajo es poner de relieve el valor literario que, en nuestra opinión, tiene la conocida inscripción de Mnesíepes, dadas sus características epigráficas y lingüísticas.

Se trata de un documento bastante curioso que ha llamado la atención a multitud de estudiosos y especialistas en Arquíloco, la lírica arcaica y la literatura griega en general, puesto que constituye la prueba de que este poeta tan importante recibió cierto culto en Paros, su isla natal, y llegó a convertirse en un personaje muy relevante en el ámbito popular, cultural y religioso de la isla durante varios siglos después de su muerte en el s. VII a.C. Además, ofrece una serie de datos sobre su vida que de una forma $u$ otra se han puesto en relación con el contenido de sus poemas.

Esta inscripción del s. III a.C. no es el único documento epigráfico que conservamos sobre Arquíloco (conocemos también la inscripción de Dócimo² y la inscripción de Sóstenes ${ }^{3}$ ), pero por lo que ha llegado hasta nosotros, sí es el más interesante y el que confirma la buena reputación que se intuía del

${ }^{1}$ Cf. por ejemplo Striano 2012.

2 SEG XXXII 828; ca. 350-300 a.C. Se trata de un epigrama funerario dedicado al poeta.

${ }^{3}$ IG XII 5, 445; s. I a.C. Presenta algunas características similares a la inscripción de Mnesíepes; todavía se discute si formaron parte del mismo monumento o no. 
poeta en la isla ${ }^{4}$. Su estado de conservación es en general bastante malo ${ }^{5}$; sin embargo, uno de sus fragmentos (la columna $\mathrm{E}_{1} \mathrm{II}$ ), de una considerable longitud, se conserva especialmente bien, está prácticamente completo y presenta la mayor parte de los rasgos que la caracterizan y la convierten en un documento único, por lo que consideramos relevante estudiarlo con cierto detalle. Su contenido es, además, bastante llamativo, pues se hace referencia al monumento en el que se inscribió este texto, el Archilocheion, y da cuenta del tipo de construcción que quizá pudo ser: una especie de heroon ${ }^{6}$ o templo dedicado al poeta, donde recibiría honores junto a algunas divinidades. En este fragmento se justifica en primer lugar la construcción del monumento por mandato de Apolo mediante la cita de tres respuestas oraculares a Mnesíepes (cf. Tabla 1), y a continuación, después de una pequeña introducción autorreferencial o metadiscursiva (cf. Tabla 2), se narra lo que podría ser el primer episodio reseñable de la vida del poeta: su iniciación en la poesía, en el arte de la lira, don entregado por las Musas (cf. Tabla 3).

\section{DESCRIPCIÓN Y CARACTERÍSTICAS DEL FRAGMENTO E $\mathrm{E}_{1} \mathrm{II}$ : LA APARICIÓN DE LAS MUSAS}

Esta inscripción no encaja fácilmente en la clasificación epigráfica tradicional. Teniendo en cuenta no sólo el contenido, sino también la forma de redacción y la presentación y distribución externa del texto en la superficie de la piedra y debido a la enorme peculiaridad de algunas de sus características, no se puede considerar una inscripción de carácter público ni privado.

${ }^{4}$ Es preciso tener en cuenta que la imagen positiva y heroificada de Arquíloco presente en los textos epigráficos contrasta bastante con la imagen que de él ha proporcionado, en general, la tradición manuscrita, ya que fue un personaje bastante polémico y controvertido en la Antigüedad debido al contenido de sus poemas. Cf. Suárez de la Torre 2002, p. 75.

${ }^{5}$ A partir del s. I a.C. el culto a Arquíloco debió disminuir, puesto que fragmentos de estas tres inscripciones han aparecido dispersos en los alrededores de Parikía y los bloques de piedra reutilizados, de ahí su enorme desgaste. Para más información sobre las inscripciones relacionadas con Arquíloco y una bibliografía abundante y actualizada sobre ellas cf. Clay 2004. Se sigue para el texto griego la edición de Ornaghi (2009) muy fiel al texto conservado en la piedra, con aparato crítico abundante, resolviendo en ocasiones algunos problemas de lectura. La traducción del texto y las fotos de la inscripción son propias. Pueden consultarse otras ediciones y traducciones en Tarditi 1968, Suárez de la Torre 2002, Carrizo 2011 o Gerber 1999.

${ }^{6}$ Para las características generales de este tipo de complejos, cf. Kearns 1992. 


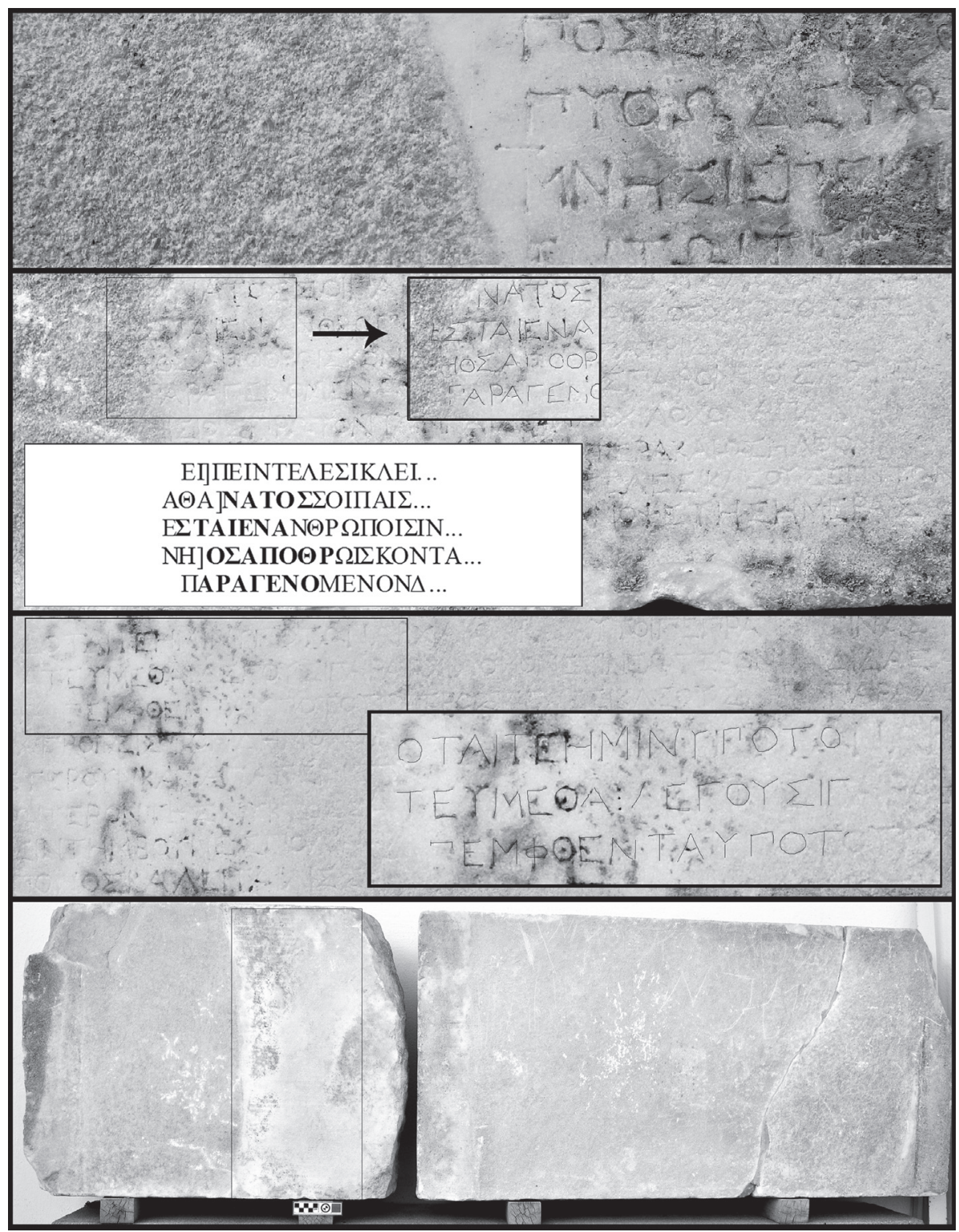

Fig. 1. Fr. $\mathrm{E}_{1} \mathrm{II}$ : Ejemplo de paragraphos, entre las líneas 7 y 8; ejemplo de ekthesis, líneas 49-53; ejemplo de interpunción, línea 22; vista general de la Inscripción de Mnesíepes (Museo Arqueológico de Paros): bloques $\mathrm{E}_{1}$ y $\mathrm{E}_{2}$. 


\section{Aproximación epigráfica: análisis de las características superficiales de la inscripción ${ }^{7}$}

Es apreciable a simple vista que el texto de los dos bloques conservados está distribuido en columnas. A pesar del estado de conservación de gran parte de la superficie de la piedra, se observa también, aunque con un poco más de esfuerzo, que algunas partes del texto están resaltadas con una diferencia de margen de una letra aproximadamente. En nuestro fragmento esto se observa al principio y al final de la columna, coincidiendo con el texto de dos oráculos: las tres respuestas de Mnesíepes (líneas 1-15) y una profecía revelada a Telesicles (50-52), mediante la cual se anuncia la gran gloria del poeta.

Por otro lado, el texto presenta una serie de marcas (pequeñas líneas rectas horizontales) en el margen izquierdo, al comienzo de algunas líneas de texto ${ }^{8}$.

Son visibles, además, varias interpunciones formadas por tres puntos colocados en posición vertical. No es posible determinar con exactitud el número concreto de interpunciones que aparecen en este fragmento debido al mal estado de conservación de la piedra ${ }^{9}$. Sin embargo, aunque en muchos casos no son claramente distinguibles, sí se puede apreciar un pequeño espacio mayor del habitual entre algunas palabras.

Aunque la superficie está muy erosionada y la incisión no es muy profunda, se puede observar que la letra es pequeña pero elegante. Esto permitió a Kontoleon, el primer editor, fechar esta inscripción en el s. III a.C. puesto que el tipo de letra es muy similar a la del Marmor Parium (IG XII 5, 444). Aunque no llega a ser stoichedon, y la extensión final de algunas líneas es variable, el texto está distribuido de manera homogénea en la superficie de la

${ }^{7}$ Para realizar este apartado han resultado muy útiles las referencias bibliográficas y las aclaraciones que nos han facilitado José A. Berenguer Sánchez (ILC-CSIC), Edoardo Cavalli y Claudia Antonetti (Laboratorio di Epigrafia greca, Università Ca' Foscari, Dipartimento di Studi Umanistici) y Diskin Clay (Duke University) a quienes agradecemos su interés y ayuda.

${ }^{8} \mathrm{Al}$ menos entre las líneas 7-8 y 13-14 se pueden ver a simple vista fácilmente. Si había más en el resto del texto no se conservan por la erosión de la piedra, ya que las primeras letras a partir de la línea 14 hasta la 52 están, en su mayoría, prácticamente borradas.

${ }^{9}$ Existe un amplio debate sobre esta cuestión por parte de los editores. En las ediciones más recientes todas estas marcas aparecen reproducidas e incorporadas al texto, pero no coinciden en esta cuestión. 
piedra, y perfectamente encuadrado por los márgenes alrededor de las columnas de texto.

Ni el tipo de marcas ni la disposición en columnas son elementos frecuentes en documentos epigráficos, pero sí son muy utilizados en otros soportes, como el papiro, por lo que han sido bien estudiadas y descritas; se conocen como ekthesis (sangría inversa en el margen izquierdo), paragraphai (pequeñas líneas horizontales al comienzo de algunas líneas) y triple (interpunciones) ${ }^{10}$. Esto ya fue advertido por el primer editor, quien trató de poner en relación y comparar ambos soportes, pues su uso es similar ${ }^{11}$.

En este fragmento, las tres marcas están perfectamente combinadas. Los oráculos, tanto el grupo de respuestas de Mnesíepes (líneas 1-15) como el de Telesicles (50-52), están resaltados con ekthesis; además, cada respuesta dada

${ }^{10}$ Aunque este tipo de marcas, salvo las interpunciones, no son muy frecuentes en epígrafes, sin duda su aparición en esta inscripción no es un hecho aislado. La paragraphos aparece en algunos catálogos y otros documentos oficiales, incluso de las Cícladas, pero no en leyes, decretos y otros documentos públicos. Además, aparece también en la gran inscripción filosófica de Enoanda, un interesante texto también en prosa que contiene algunas enseñanzas de Epicuro y en la que se observan también estas marcas. La ekthesis también está presente al menos en otras dos inscripciones: una inscripción procedente de Calatis y la inscripción de la historia de la fundación de Magnesia, donde se utiliza para resaltar algunas partes del texto, incluso oráculos (cf. Clay 2004, p. 156, nota 16). Estas tres inscripciones podrían ponerse fácilmente en relación con la inscripción de Mnesíepes por el carácter peculiar de su forma y de su contenido. Por otro lado, la coronis (que aparece en otro fragmento de la inscripción), junto con otras marcas de tipo decorativo, aparece por ejemplo en las leyes de Gortina separando distintas partes del texto; también aparece en alguna inscripción funeraria limitando los nombres de los difuntos, en una inscripción pública de Léucade y en una defixio ática inscrita en una laminilla de bronce que imita, precisamente, a un rollo de papiro (Cf. Baldassarra 2010, pp. 363-364).

${ }^{11}$ La distribución en columnas es el sistema habitual de escritura empleado en los rollos de papiro, pero en el caso de los manuscritos literarios, este sistema es invariable (Kenyon 1970, pp. 20-21); aunque Clay (2004, p. 11) observa, sin embargo, que la extensión de las columnas (es decir, el número de líneas por columna) es algo mayor que la que se encuentra normalmente en los papiros. La paragraphos y los tres puntos verticales son las marcas de las que tenemos constancia más temprana, al menos desde comienzos del s. III a.C., utilizadas a menudo en papiros literarios para marcar una separación o pausa, un cambio o un giro en el sentido del texto, para pasar de una parte a otra, de un capítulo a otro, de un canto a otro e incluso, las distintas intervenciones de los actores de una obra dramática, o el final de cada estrofa, antístrofa o epodo de un poema; mientras que la ekthesis (hacia fuera) y la eisthesis (hacia dentro) se utilizaban desde mediados del s. III a.C. en textos versificados y en documentos, comentarios o listas para señalar una nueva entrada (Turner 1971, pp. 9 ss). 
a Mnesíepes está marcada por paragraphai (entre las líneas 7-8 y 13-14) e interpunciones (al final de las líneas 7, 13 y 15) ${ }^{12}$. Las interpunciones son más numerosas y marcan un cambio en el contenido del texto: en la línea 16 el texto continúa con la interpretación de los oráculos de Mnesíepes y la justificación de su composición por escrito que termina a mitad de la línea 22, en la que por medio de otra interpunción se da paso al relato de las Musas, centrado en Arquíloco. No vuelve a aparecer este elemento hasta la línea 40, donde marca un cambio de personajes y la acción la protagoniza Telesicles. Hay dos interpunciones más, en la línea 43, momento en el que los ciudadanos deciden enviar a Telesicles y a Licambes a Delfos, y en la línea 47, cuando Telesicles, ya en Delfos, recibe la profecía de la divinidad. Esto, como veremos más adelante, demuestra una ordenación previa del texto, muy precisa y cuidada, y cabe preguntarse si el texto de la inscripción de Mnesíepes en algún momento circuló en otro soporte hasta que finalmente se puso por escrito en piedra, trasladando a este material imperecedero también su aspecto y configuración externa, no sólo su contenido.

\section{Análisis de las características lingüisticas y discursivas del texto}

\subsection{Estructura externa y delimitación dialectal}

Como hemos visto, este fragmento presenta dos partes claramente diferenciadas por la primera ekthesis: el encabezamiento del texto, que está compuesto por las tres respuestas oraculares a Mnesíepes (líneas 1-15), y el episodio narrativo sobre la supuesta vida del poeta, lo que llamaremos a partir de ahora «cuerpo del texto» (16-57). Sin embargo, ambas partes no sólo están resaltadas tipográficamente: se observa también una alternancia en el uso de formas dialectales distintas ${ }^{13}$.

${ }^{12}$ Cuando la paragraphos es aparentemente redundante como en este caso, puesto que la unidad de sentido ya está delimitada por la interpunción, se podría considerar una ayuda para orientar la lectura (en voz alta) y avisar al lector del final de una pequeña unidad de texto (cf. Johnson 1994).

${ }_{13}$ También se introducen en el texto de la inscripción, al igual que en la inscripción de Sóstenes, algunas citas directas en verso o fragmentos de poemas de Arquíloco utilizados en ambas inscripciones para ilustrar algunos episodios de la historia de Paros del s. VII a.C. Están redactadas en dialecto jonio, pero un jonio literario, pues la lengua presente en los poemas de Arquíloco es una lengua literaria que no tiene por qué corresponderse exactamente con el 
Las respuestas oraculares de Mnesíepes, transmitidas en prosa, están redactadas en un dialecto noroccidental: aparece la forma de infinitivo $\varepsilon \tilde{i} \mu \varepsilon v$

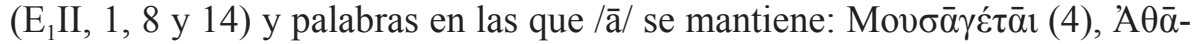

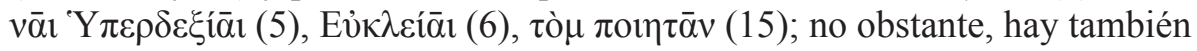

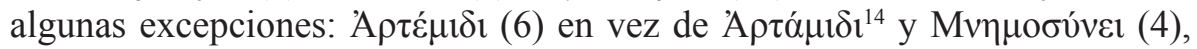
con $/ \overline{\mathrm{e}} /$ abierta $^{15}$. A pesar de estos casos aislados, parece claro, en nuestra opinión, que el autor se esforzó en elaborar un oráculo verosímil y lo más cercano posible a esa realidad délfica ${ }^{16}$ : introdujo elementos dialectales y seleccionó cuidadosamente los términos y fórmulas típicos de las respuestas oraculares, tal y como conservamos en inscripciones de Delfos, Dodona o Dídima. Aunque puede presentar variantes, los dos comparativos que aparecen aquí y el orden en el que aparecen es lo más frecuente, al igual que la

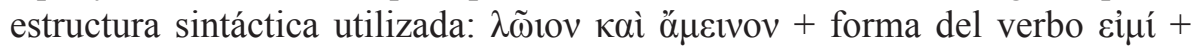
pronombre o nombre del consultante en dativo + participio (a veces infinitivo) que concierta con el dativo anterior e indica lo que se debe o no hacer ${ }^{17}$. En este caso, la respuesta se inicia con el nombre del consultante, receptor del

dialecto local de la isla. Esos rasgos dialectales pueden estar condicionados por el metro o por influencias de otros géneros y autores (cf. Cassio 2008); sin embargo, en el fragmento que nos ocupa estas citas no están presentes, de modo que no se van a comentar en este trabajo.

${ }^{14}$ Esta forma, resultado posiblemente de una asimilación a-e $>$ a-a es pronto suplantada

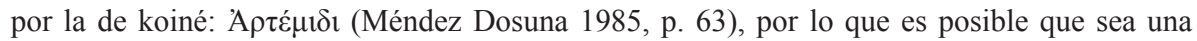
forma lingüística aún más precisa del dialecto délfico de la época.

${ }^{15}$ No tenemos en cuenta el nombre de Mnesíepes, que presenta también /ē/ abierta en

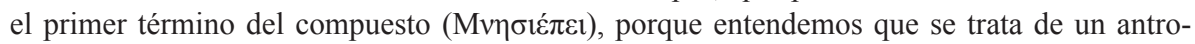
pónimo en dialecto local. Sin embargo, sí es reseñable que precisamente el nombre de esta divinidad (Mnemosine) presente la misma variante que el receptor del oráculo (cf. nota 22), muestra, quizá, de la artificialidad del texto.

${ }^{16}$ La construcción de un monumento sagrado en honor de un mortal se debe justificar; por ello, al introducir estas tres respuestas de Delfos, se hace constar que no sólo la divinidad permite y legitima este acto sino que incluso lo dispone así mediante un oráculo. Es necesario reflexionar sobre la verosimilitud de estas tres respuestas: ¿se cita, de manera directa, una ratificación real del oráculo o se trata de una invención del redactor/compilador del texto para dar solidez y unidad al conjunto de la inscripción y el monumento? En cualquier caso, el resto de los oráculos de la inscripción parece que pertenecían a la tradición arquiloquea de la isla, mientras que este no; se compuso (en ¿Delfos? o en Paros) en el s.III a.C. exclusivamente para este propósito.

${ }_{17}$ Eidinow (2007, p. 52) hace referencia precisamente a estas tres respuestas oraculares, tomándolas como ejemplo de las respuestas oraculares de Delfos. Para la estructura formular general de los oráculos cf. Lhôte 2006, p. 339 y 426. 
oráculo, pero inmediatamente se introduce a Apolo, también mediante una expresión frecuente en los oráculos de Delfos, en la que no hace falta explicitar

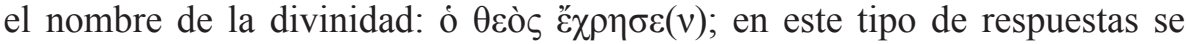
suele mencionar a continuación una lista de dioses y se dice cómo rendirles culto $^{18}$. Todo ello está presente en este fragmento.

En la última de las tres respuestas, precisamente en la que se menciona a Arquíloco, se introduce una variatio: la respuesta es más breve (sólo dos líneas), y aunque el encabezamiento es el mismo, no se menciona la fórmula final de agradecimiento que sí está presente en las otras dos respuestas

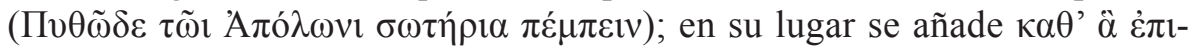
voeĩ, de cierto carácter conclusivo, lo que serviría para indicar que el proyecto del Archilocheion, decidido con antelación, ya se habría dado a conocer al oráculo y estaba pendiente de su aprobación (esto era un procedimiento habitual).

\section{Tabla 1. Respuestas oraculares de Mnesíepes ( $\mathrm{E}_{1} \mathrm{II}$, líneas 1-15)}

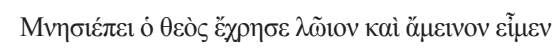

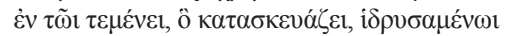

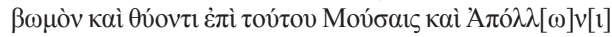

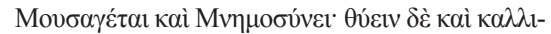

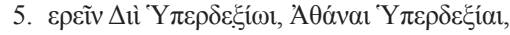

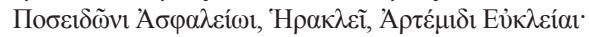

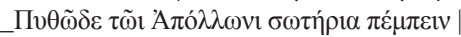

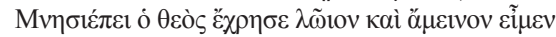

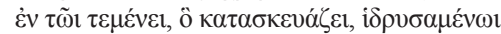

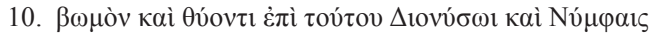

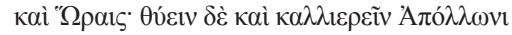

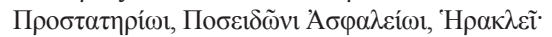

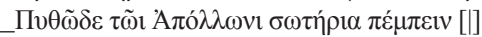

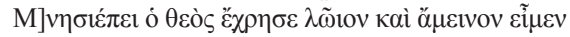

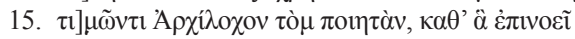

La divinidad proclamó a Mnesiepes que lo más conveniente y lo mejor era, en el recinto sagrado que estaba construyendo, colocar un altar y sobre este ofrecer sacrificios a las Musas, a Apolo, conductor de las Musas y a Mnemosine; ofrecer sacrificios favorables (5) a Zeus Hiperdexio, a Atenea Hiperdexia, a Poseidón Asfaleo, a Heracles y a Ártemis Eucleia, (y) enviar a Delfos sacrificios en acción de gracias a Apolo.

La divinidad proclamó a Mnesiepes que lo más conveniente y lo mejor era, en el recinto sagrado que estaba construyendo, colocar un altar (10) y sobre este ofrecer sacrificios a Dioniso, a las Ninfas y a las Horas; ofrecer sacrificios favorables a Apolo Prostaterio, a Poseidón Asfaleo y a Heracles, (y) enviar a Delfos sacrificios en acción de gracias a Apolo.

La divinidad proclamó a Mnesíepes que lo más conveniente y lo mejor era (15) honrar al poeta Arquíloco según lo estipulado.

${ }^{18}$ Sobre la relación entre Arquíloco y las divinidades mencionadas en la inscripción cf. Guarducci 1967- 1978, vol. IV, p. 89 y Privitera 1966. 
Por otro lado, conviene destacar también la precisión en las palabras atribuidas a la divinidad: al hacer referencia a los dioses se utiliza el verbo $\theta v ́ \omega$, mientras

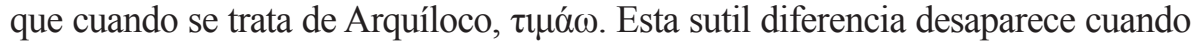
se afirma en el cuerpo del texto unas líneas más abajo que, tras haber conocido la respuesta de este oráculo, se decide hacer ofrendas y sacrificios tanto a los dioses como a Arquíloco, además de honrar al poeta ( $\left.\mathrm{E}_{1} \mathrm{II}, 16-19\right)$.

El resto del texto de este fragmento está redactado de manera homogénea en ático, rasgo que comparte con la inscripción de Sóstenes ${ }^{19}$. Están presentes

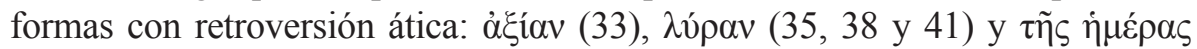

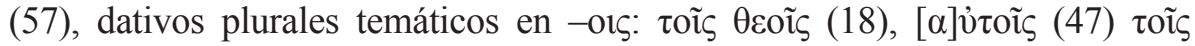
A $\rho \tau \varepsilon \mu 1 \sigma i ́ o r \varsigma ~(54)$, formas con metátesis de cantidad: $\dot{\pi} \varepsilon \rho \rho \tilde{\eta} \varsigma \pi$ ó $\lambda \varepsilon \omega \varsigma$ (45), formas en $-\varepsilon \alpha$ contraídas y regularización morfológica: $\tau o ̀ v ~ T \varepsilon \lambda \varepsilon \sigma 1 \kappa \lambda \tilde{\eta} v$ (40), la forma de participio ǒv $\tau \alpha$ (23), la preposición eiৎ $(24,27,30 \ldots)$ y aspiración

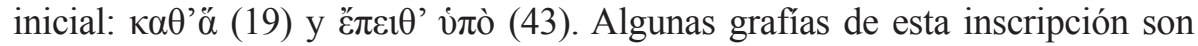
típicas de las inscripciones áticas de esta época: la grafía $<\mathrm{H}>$ del aumento en

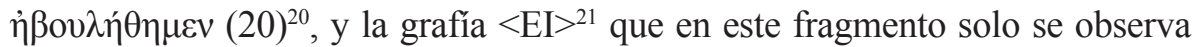

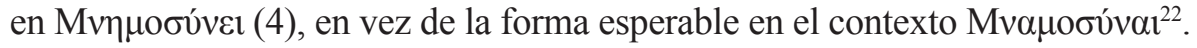

Parece que el dialecto jonio es el que se vio más influenciado por la koiné y el que adoptó más rápidamente su colorido ático, pero todavía más el del

19 Algunos de los rasgos lingüísticos comentados son adoptados por la koiné, pero queremos llamar la atención sobre el hecho de que no se aprecia ningún jonismo. En la inscripción de Sóstenes (fr. AIV, 16) se lee $\dot{\eta} \tau \tau[\dot{\eta}] \theta \eta$, con un rasgo típicamente ático difícilmente explicable, puesto que en koiné normalmente se evita en favor de la forma jonia con doble sigma.

${ }^{20}$ Esta grafía es más frecuente que $<\mathrm{E}->$ en las inscripciones áticas después de 330 a.C.

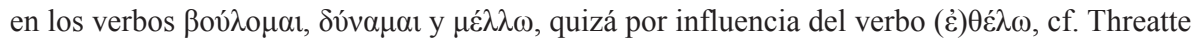
1996, vol. II, p. 474.

${ }^{21}$ Comienza a utilizarse en inscripciones áticas a finales del s. V a.C. para notar el diptongo de primer elemento largo /êi/; esta grafía es más frecuente a partir del s. IV y sobre todo en el s. III a.C., cf. Threatte 1980, vol. I, p. 377. Otros ejemplos de ello en $\mathrm{E}_{1}$ III: posiblemente

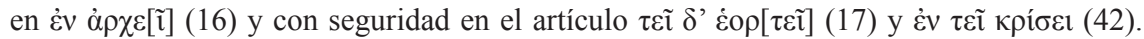

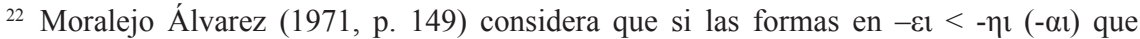
aparecen en délfico son aticismos, es de notar la rapidez con la que este dativo se extiende a otras zonas geográficas. Parece que, en términos fonéticos, la abreviación de este diptongo es común a otros dialectos griegos en época helenística, ya que la grafía $<$ EI $>$ también está presente en esta época en inscripciones en dorio noroccidental (cf. Méndez Dosuna 1985, cap. 4, pp. 413-463). Podría tratarse de un lapsus influido por la koiné de la época (forma ática en contexto dialectal dorio) pero podría tratarse, de nuevo, de otro ejemplo de la precisión lingüística presente en esta inscripción (cf. notas 14 y 15), aunque no podemos obviar la sospechosa presencia de /ê/ abierta y no /â/ en esta palabra. 
ámbito insular donde se observa que algunas inscripciones ya presentan rasgos inequívocamente áticos al menos desde el s. V a. C. La influencia que Atenas ejerce sobre las Cícladas es muy importante, no sólo política y administrativamente, sino también desde el punto de vista cultural y lingüístico, puesto que los aticismos están presentes tanto en documentos de carácter público como privado $^{23}$. Además, el hecho de que esta inscripción repleta de aticismos, aunque se transmite la historia de un personaje local, no esté redactada en el dialecto local, puede que tampoco sea casual ${ }^{24}$. El empleo del ático en este caso era una garantía para la difusión del texto y es posible que fuera la mejor manera de internacionalizarlo, y dotarlo, junto con el monumento y la leyenda sobre Arquíloco, el héroe local, de cierto atractivo turístico.

\subsection{Desarrollo de la secuencia narrativa ( $\left.\mathrm{E}_{1} \mathrm{II}, 16-57\right)$}

Tras las respuestas oraculares de Mnesíepes, el cuerpo del texto comienza con una pequeña introducción, entre interpunciones.

Tabla 2. Introducción previa a la narración ( $\mathrm{E}_{1} \mathrm{II}$, líneas 16-22)

\begin{tabular}{|c|c|c|}
\hline 20. & 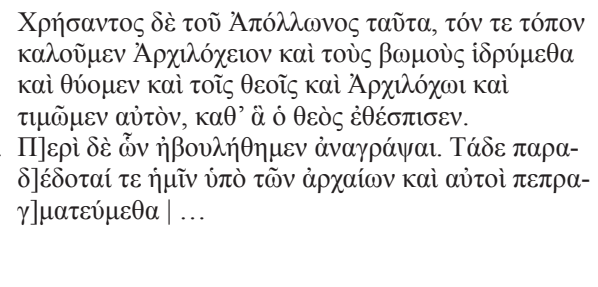 & $\begin{array}{l}\text { Habiendo anunciado Apolo estas cosas, lla- } \\
\text { mamos al lugar Archilocheion, y establece- } \\
\text { mos altares y hacemos sacrificios tanto a los } \\
\text { dioses como a Arquíloco, y honramos a este } \\
\text { según lo que la divinidad nos ha ordenado. } \\
\text { (20) Queremos escribir sobre estas co- } \\
\text { sas, las que nos han sido transmitidas } \\
\text { por los antiguos y que nosotros mismos } \\
\text { hemos elaborado. }\end{array}$ \\
\hline
\end{tabular}

23 Todavía no se dispone de un estudio reciente y exhaustivo sobre el dialecto de estas islas, pero la importante e inusual presencia del ático en los documentos escritos de las Cícladas desde época temprana es un hecho constatable. Cf. López-Eire 1993, p.43.

24 Parece que el autor del texto era plenamente consciente de la utilización de registros diferentes para cada situación. El oráculo de Telesicles también está resaltado mediante ekthesis; se transmite directamente en verso (tres hexámetros dactílicos), y no presenta ni rasgos dialectales

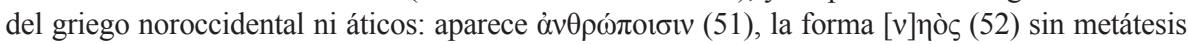

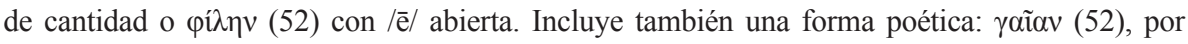
necesidades métricas. Así podría explicarse también la introducción de las formas aparentemente

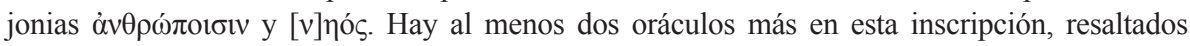
también con ekthesis ( $\mathrm{E}_{1}$ III 31-35 y 47-50), pero lamentablemente están incompletos. 
El redactor del texto trata de justificar la construcción del Archilocheion y los honores que recibe el poeta en la isla interpretando explícitamente las palabras de la divinidad. Además, da a conocer las fuentes utilizadas y el objetivo por el que se pone por escrito este texto (dejar constancia de un pasado común transmitido de generación en generación) reelaborando la tradición ${ }^{25}$. Lo más llamativo es el sujeto de los verbos utilizados, una primera persona de plural difícil de explicar, puesto que, en definitiva, depende de la interpretación que se haga del propio monumento. Según algunos estudiosos hace referencia a un grupo de dedicantes entre los que se encontraba Mnesíepes, aunque en nuestra opinión se pudo introducir con el fin de incluir y hacer partícipe a la comunidad, al conjunto de la sociedad de la isla.

Inmediatamente después de esta introducción se refieren los acontecimientos y episodios relacionados con el poeta. Da la impresión de que el relato de las Musas era el primero de ellos y presenta todos los elementos prototípicos de una narración.

Se da paso a un narrador externo en tercera persona, que se limita a relatar lo sucedido. Este cambio es introducido por $\lambda \varepsilon ́ \gamma o v \sigma ı v$, en primera posición. Esta expresión, y sus múltiples variantes, es universal y se utiliza con mucha frecuencia para introducir cuentos y leyendas como técnica narrativa que implica un alejamiento del narrador con respecto a lo narrado, donde la veracidad de los hechos no es lo más relevante, sino, de nuevo, su verosimilitud. También en este sentido se utilizan ciertas estrategias para dar apariencia de realidad.

El texto está perfectamente estructurado, y los acontecimientos siguen un orden cronológico; se puede diferenciar una estructura tripartita típica, con presentación, nudo y desenlace (aunque la narración está incompleta). La acción gira en torno a un personaje principal (Arquíloco), y todo lo que se narra guarda relación con él, aunque se mencionan también los nombres de otros personajes relacionados con la aristocracia de la isla: Telesicles y Licambes (padre y suegro de Arquíloco respectivamente según la tradición); estos son enviados a Delfos como theopropoi (consultantes elegidos por la

${ }_{25}$ Todo esto podría considerarse una sutil captatio benevolentiae, pues no es la única que podemos leer en la inscripción: al comienzo del fragmento $\mathrm{E}_{2} \mathrm{I}$ (líneas 1-4) se intuye otra fórmula retórica típica de los discursos epidícticos, cf. reconstrucción del texto en Clay 2004. 


\section{Tabla 3. Secuencia narrativa (E1II, líneas 22-57)}

\begin{tabular}{|c|c|}
\hline 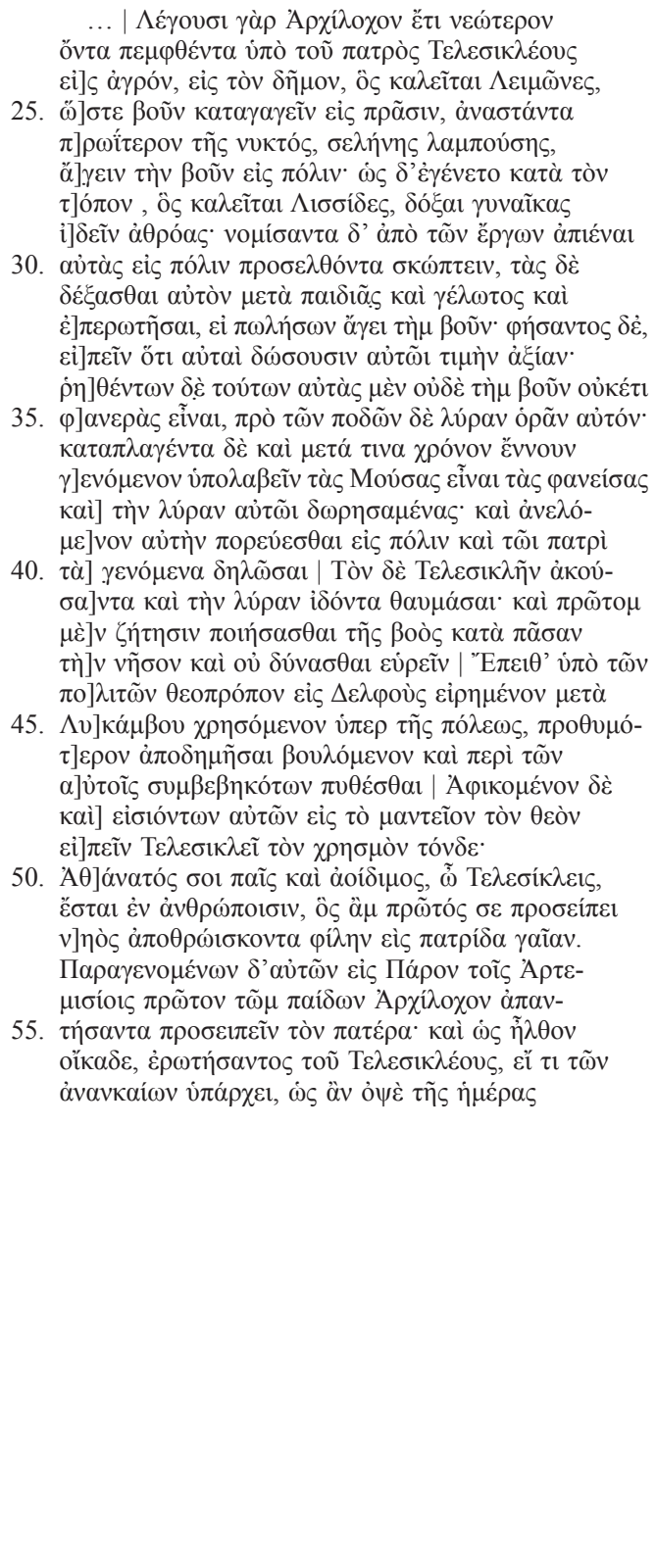 & $\begin{array}{l}\text { Así pues, dicen que Arquíloco, siendo } \\
\text { todavía joven, enviado por su padre Tele- } \\
\text { sicles al campo, al demo que se llama Li- } \\
\text { mones (25) con el fin de llevar una vaca } \\
\text { para ponerla en venta, levantándose muy } \\
\text { temprano, cuando todavía era de noche } \\
\text { y brillaba la luna, condujo la vaca a la } \\
\text { ciudad; y sucedió que cuando estaba en } \\
\text { un lugar que se llama Lisides, le pareció } \\
\text { ver a unas mujeres reunidas, y creyendo } \\
\text { que ellas regresaban a la ciudad después } \\
\text { de sus labores, (30) acercándose a ellas } \\
\text { bromeó, pero ellas le recibieron con jue- } \\
\text { gos y risas, y le preguntaron si llevaba } \\
\text { la vaca para venderla; al decir que sí, le } \\
\text { dijeron que ellas le iban a dar un precio } \\
\text { digno. Nada más pronunciar estas pala- } \\
\text { bras, tanto ellas como la vaca (35) desa- } \\
\text { parecieron y delante de sus pies vio una } \\
\text { lira. Sorprendido, vuelto en sí después de } \\
\text { algún tiempo, comprendió que eran las } \\
\text { Musas las que se le habían aparecido y } \\
\text { le habían regalado la lira, y tras recogerla } \\
\text { se encaminó a la ciudad (40) y le explicó } \\
\text { a su padre lo sucedido. Tras escucharlo y } \\
\text { ver la lira, Telesicles quedó sorprendido. } \\
\text { En primer lugar buscó la vaca por toda la } \\
\text { isla y no pudo encontrarla, después, ele- } \\
\text { gido por los ciudadanos como teopropos } \\
\text { (para ir) a Delfos (45) junto con Licam- } \\
\text { bes a consultar al oráculo en nombre de } \\
\text { la ciudad, viajó muy diligente queriendo } \\
\text { también averiguar (algo) acerca de lo que } \\
\text { rado algo de lo necesario, puesto que el } \\
\text { día estaba ya muy avanzado... } \\
\text { (ambosía sucedido. Tras llegar y entrar } \\
\text { los, la divinidad le dijo a Telesicles esta } \\
\text { sias, el primero de los hijos que saludó } \\
\text { profecía: } \\
\text { (50) Tendrás un hijo inmortal y digno } \\
\text { de ser celebrado entre los hombres, Te- } \\
\text { lesicles, el cual te saludará el primero } \\
\text { tierra patria. }\end{array}$ \\
\hline
\end{tabular}


ciudad para consultar un oráculo) ${ }^{26}$, lo que sirve como estrategia narrativa para avanzar en la acción e introducir uno de los oráculos de la tradición arquiloquea, con el que se presagia la gran gloria del poeta.

La pretendida precisión temporal y espacial también es llamativa: Delfos y Paros aparecen mezclados con otros dos lugares que no han podido ser identificados: el demo de Limones («Praderas») y Lisides («¿Rocas pulidas?»), donde se produce el encuentro con las Musas, pues se trata de referencias locales muy concretas pero al mismo tiempo algo imprecisas ${ }^{27}$. Por otra parte, la narración se sitúa en la época en la que vivió Arquíloco, un pasado bastante alejado para un autor del s. III a.C. pero además, en el texto también se ofrecen datos temporales muy concretos que encuadran el suceso perfectamente en un momento determinado: Arquíloco se levantó «muy temprano, cuando todavía brillaba la luna» para llevar la vaca al campo (26), el encuentro con las mujeres se produjo «después de que estas hubieran terminado sus labores» (29) y Telesicles regresa de Delfos «durante las Artemisias» (53-54). Este esfuerzo continuo por parte del redactor por dar más realismo a la narración se corresponde, en nuestra opinión, con la precisión lingüística presente en los tres oráculos de Mnesíepes.

Otro de los aspectos destacables de este episodio es el estilo de redacción. Las marcas que se emplean a lo largo de todo el fragmento (paragraphai, ekthesis, interpunciones...) están combinadas con una serie de partículas y marcadores del discurso, poco frecuentes también en textos epigráficos, que contribuyen a distribuir, organizar y cohesionar el contenido, haciéndolo ameno y fácil de seguir. Abunda la conjunción coordinante $\delta \dot{\varepsilon}(16,20,27,29,30,32,34,35,36,40,47,53)$ que en ocasiones aparece en correlación con la partícula $\mu \varepsilon ́ v(34,42)$ con el fin de organizar y relacionar algunas oraciones entre sí; aparece también la partícula enclítica $\tau \varepsilon$ (21), y una correlación temporal con $\pi \rho \tilde{\omega} \tau o v ~(41)$... ह̌ $\pi \varepsilon \imath \tau \alpha$ (43). La colo-

${ }^{26}$ Los parios enviaban embajadores a Delfos con cierta frecuencia para preguntar sobre los asuntos que concernían a la ciudad (Hansen y Nielsen 2004, p. 766), pero esto no implica necesariamente que la consulta se llevara a cabo. Además, si se esconden o no bajo estos antropónimos personajes reales ha sido objeto de un amplio debate (para más información cf. Carrizo 2011, p. 141, nota 74). En nuestra opinión, el hecho de que aparezcan mencionados precisamente en esta inscripción tan especial no implica necesariamente su existencia real.

${ }^{27} \mathrm{Su}$ existencia real tampoco es demostrable. Para más información sobre estos topónimos, su etimología y sus posibles implicaciones rituales cf. Miralles y Pórtulas 1983, pp. 65-69. 
cación de estas partículas se corresponde en varias ocasiones con alguna interpunción (en las líneas 40, 43 y 47), sin embargo, lo más llamativo es la presencia de la partícula yó $\rho$ en la línea 22 tratando de llamar la atención del lector, justo después de $\lambda \dot{\varepsilon} \gamma o v \sigma 1$, verbo precedido además por una interpunción que se observa con bastante claridad en el texto. Esta partícula se utiliza aquí, como en los textos literarios griegos que conocemos, para resaltar y centrar la atención en lo importante: el relato sobre Arquíloco, dejando a un lado todo lo dicho en las líneas anteriores. Asimismo, son muy frecuentes en el texto las construcciones de participio y de infinitivo (en general, completivas que dependen de $\lambda \dot{\varepsilon} \gamma \sigma v \sigma \iota)$, y otras oraciones subordinadas, como la completiva de la línea 33, introducida por ő $\tau 1$, y oraciones introducidas por un pronombre relativo. Todo ello demuestra una sintaxis compleja y por tanto, muy cuidada y elaborada.

No es frecuente encontrar documentos epigráficos en prosa con estas características lingüísticas propias de un verdadero texto narrativo, así como otros elementos poéticos, introducidos únicamente por motivos estéticos. En las respuestas oraculares de Mnesíepes, por ejemplo, destaca el lenguaje formular y repetitivo, aparentemente estático, unido a los epítetos de los distintos dioses y la utilización del término $\Pi v \theta \tilde{\omega} \delta \varepsilon$, con esa forma casual fosilizada, homérica; pero también en el cuerpo del texto, lleno de anécdotas y elementos de carácter maravilloso, hay algunas expresiones poéticas: en la línea 26, por ejemplo, se utiliza una expresión perifrástica mediante una construcción de genitivo absoluto para indicar que Arquíloco se levanta muy tempano: $\pi] \rho \omega i ̂ ́ \tau \varepsilon \rho o v ~ \tau \tilde{\eta} \varsigma ~ v v \kappa \tau o ́ \varsigma, ~ \sigma \varepsilon \lambda \eta ́ v \eta \varsigma ~ \lambda \alpha \mu \pi o v ́ \sigma \eta \varsigma$. El estilo de redacción presente en este fragmento ha llamado la atención a muchos estudiosos, pero Giannisi (2004, p. 125), a pesar de que no desarrolla la idea, afirma algo que nos parece fundamental en relación con los textos del Archilocheion: "The inscriptions were part of a monument that had to do with the making of poetry, being a poetic product by themselves».

Por último, resulta interesante mencionar brevemente las reminiscencias de este pasaje con otras composiciones literarias bien conocidas como el Himno Homérico a Hermes (IV) y el proemio de la Teogonía (vv. 1-36) ${ }^{28}$.

${ }^{28}$ Se observan algunos elementos comunes: el intercambio entre la lira y la vaca y el encuentro con las Musas como momento de iniciación en la poesía, de noche y cuando el poeta está solo y a cargo del ganado. Además las Musas, fuente de inspiración poética, están presentes con frecuencia en composiciones épicas y líricas, lo que se convirtió en una convención literaria. 


\section{La leyenda de Arquíloco de Paros y SU tradición}

Se dice del fragmento $E_{1} I I$ que posee algunos rasgos típicos del cuento popular, por los elementos fantásticos y maravillosos que presenta ${ }^{29}$. Sin embargo, parece conveniente matizar esta afirmación un poco más. En cuanto al tipo de texto, se observa una diferencia clara entre (a) los oráculos de Mnesíepes, junto con su interpretación, la mención del Archilocheion y la justificación del texto (en primera persona de plural) y (b) la narración del episodio de las Musas del cuerpo del texto.

Parece claro que debía de existir algún tipo de relato tradicional transmitido de generación en generación a través de los siglos que posiblemente empezó a configurarse tras la muerte del poeta, quien seguramente había alcanzado ya cierta fama dentro y fuera de la isla. Como de cualquier relato trasmitido oralmente, es muy probable que existieran muchas versiones, en función del número de transmisores, y que, con el tiempo, se le fueran añadiendo pequeños detalles, según el interés y la funcionalidad que se quisiera volcar en la narración en cada momento, como por ejemplo, captar la atención del público con elementos efectistas o asombrosos, relacionar la figura de Arquíloco con determinado dios o convertirlo en instaurador de un determinado culto, o destacar la faceta guerrera y valiente del poeta en determinadas situaciones bélicas estableciendo un modelo a seguir (todos estos elementos están presentes, de alguna manera, en los fragmentos conservados de la inscripción de Mnesíepes) ${ }^{30}$.

Actualmente no disponemos de otras versiones de este relato, por lo que no es posible ni reconstruir la forma original o versión más extendida que pudo tener, si es que la tuvo en algún momento y difería en algo de esta, ni dar cuenta de los cambios que ha sufrido (ni cuántos, ni cuáles ni de qué tipo), a pesar de que los distintos añadidos pudieron haber sido sustanciales para la configuración que nos ha llegado por escrito. Además, tampoco conservamos

${ }^{29}$ El episodio de Cérano y el delfín, en la inscripción de Sóstenes (fr. AI), tiene características similares.

${ }^{30}$ El texto de esta inscripción presenta un estadio ya consolidado y estructurado del proceso de «delfización» o conexión entre Arquíloco y Apolo délfico, que debió prosperar e imponerse en algún momento como trasfondo cultural y religioso de la tradición «biográfica» del poeta en la isla, cf. Lanzillotta 1987, y concretamente p. 45. También pudo ocurrir lo mismo con la imagen heroica y valiente del poeta en la guerra, visible sobre todo en la inscripción de Sóstenes. 
el texto completo de esta inscripción, solo disponemos de parte del episodio en el que se narra el encuentro de Arquíloco con las Musas, por lo que todo análisis basado en este fragmento solo puede ofrecer resultados parciales. No obstante, se observa un patrón narrativo reconocible no sólo en el mundo griego: un mortal abordado por la divinidad, que interviene de manera decisiva en su vida (Williams 1994) y, además, se pueden reconocer temas o elementos más o menos comunes presentes en esta narración, es decir, algunos motivos típicos y universales del cuento popular ${ }^{31}$. En este sentido resulta muy interesante la utilización que se hace de la profecía, que anuncia la futura grandeza del héroe y que presagia futuros acontecimientos. Estos elementos son parte de la fe de los pueblos y cuando aparecen en los cuentos no se cuestionan, se citan como prueba verdadera del suceso maravilloso al que hacen referencia; siempre provienen de un personaje o entidad muy piadosa de la que se cree que realmente ha traspasado el velo de lo desconocido (y en este caso la profecía proviene de un oráculo, ni más ni menos) $)^{32}$.

31 Semidioses o héroes culturales (A500-599), engaños por disfraz o ilusión (K18001899), concretamente dioses o santos disfrazados que visitan a mortales, sucesos extraordinarios o incidentes maravillosos (F900-1099), es decir, leyendas de santos, maravillas físicas de tipo mágico, presumiblemente debidas a la divinidad, y transformaciones (por lo general se trata de motivos subsidiarios, pero en algunas ocasiones, como esta, constituyen el interés central de la narración), intercambios de objetos y animales (D810-859), cambios de fortuna, futuro establecido y azar y destino (series L, M y N respectivamente). Se sigue la clasificación tradicional de Thompson (1955 y 1972) que preferimos a la de Uther (2004).

32 Se conservan muchas respuestas oraculares que forman parte de narraciones tradicionales que presentan rasgos característicos del cuento y la leyenda popular, aunque se simule que se trata de una narración sobre hechos históricos (Fontenrose 1978). El oráculo de Delfos se convirtió en un recurso literario habitual del que se sirvieron multitud de narradores y cuentacuentos, y las profecías y otras revelaciones, en los temas favoritos. A menudo, se añadieron oráculos y profecías a relatos que en principio no los tenían y con el tiempo se integraron de tal manera en el relato que llegaron a ser una parte fundamental del contenido de la historia; es quizá lo que ocurrió con los oráculos intercalados en esta narración sobre Arquíloco, en concreto el que anuncia la fama del poeta $\left(\mathrm{E}_{1} \mathrm{II}, 50-52\right)$, pero también los del resto de fragmentos, utilizados de manera similar. En cuanto a las tres respuestas de Mnesíepes, ajenas a la tradición popular relacionada con el poeta, posiblemente fueron redactadas ad hoc para justificar la construcción del Archilocheion, y dar sentido (político, religioso y cultural) y unidad (estética y literaria) al monumento en su conjunto y al texto de la inscripción en particular. La autenticidad o no de estas respuestas queda en segundo plano si consideramos que la construcción de este monumento podría estar promocionada por el propio santuario de Apolo, ya que en esta época había perdido bastante popularidad. Según el texto de la inscripción, el 
En nuestra opinión, la mejor manera de clasificar esta tradición popular sobre Arquíloco sería considerándola una leyenda, debido a su carácter eminentemente local, ajena en gran medida a motivos más universales presentes en el cuento y muy ligada al poeta y a la isla de Paros. Tanto es así que aunque lo que se cuenta por medio de leyendas es muy cercano a la ficción, normalmente se hace un gran esfuerzo de localización y de otros medios para sugerir que estamos oyendo un relato verdadero, y a menudo se recurre a la autoridad de los antepasados.

Existieron en el mundo griego otras narraciones y anécdotas sobre personajes reales que no llegaron a convertirse en leyendas, sin embargo, en el caso de Arquíloco sí, quizá por su enorme trascendencia, que provocó todo tipo de reacciones en el mundo antiguo. Por otro lado, algunas de las narraciones populares han permanecido en un nivel puramente oral, mientras que otras se han hecho un hueco en la literatura ${ }^{33}$.

IV. El PASO DE LA ORALIDAD A LA ESCRITURA.

CONSIDERACIONES EN TORNO AL REDACTOR DEL TEXTO

Para que una narración popular se consolide debe ser lo suficientemente estable; el narrador que lo transmite ha tenido que escuchar el relato en varias ocasiones y de varias personas diferentes, por lo que a menudo ha tenido acceso a versiones distintas. En ocasiones, un narrador con cierto talento para contar este tipo de historias puede influir en este proceso. Cualquier narración debe tener, para sobrevivir durante mucho tiempo, cierta unidad lógica y artística que un narrador hábil sabe aprovechar, de manera que la versión de semejante narrador se populariza y favorece la retención de todas las partes fundamentales del cuento (Thompson 1946, p. 553-554). Además, si se pone por escrito, como en este caso, y se expone de forma pública, tal versión queda fijada y se vuelve definitiva, es decir, se convierte en la versión oficial, de referencia. Es posible, también, que este narrador introdujera algunos elementos originales o simplemente, por el hecho de seleccionar solo

culto a Arquíloco estaba íntimamente ligado al santuario de Apolo, que posiblemente asumió los costes de la construcción del Archilocheion y de la inscripción.

${ }^{33}$ En el mundo griego también otros personajes recibieron cierto culto (sobre todo la mítica y misteriosa figura de Homero), pero los testimonios que lo evidencian no son ni tan largos, ni tan específicos, ni tan «reales» como lo es esta inscripción de Paros. 
una de las versiones relativas a algún episodio, e incluso por introducir la narración de determinada manera, se entiende, en nuestra opinión, ese recla-

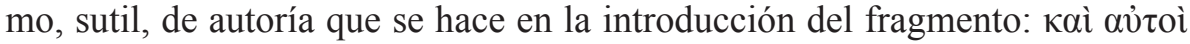
$\pi \varepsilon \pi \rho \alpha \gamma \mu \alpha \tau \varepsilon v ́ \mu \varepsilon \theta \alpha$ (y nosotros mismos hemos elaborado).

Todo lo que se ha ido comentando a lo largo de este trabajo es prueba suficiente para poder afirmar que en la inscripción de Mnesíepes se utiliza un registro culto y cuidado del griego de la época. El uso de las variaciones dialectales adecuadas en cada momento, el empleo de fórmulas y epítetos, de recursos estilísticos, perífrasis y descripciones con cierto colorido poético, el conocimiento de la literatura griega, la épica y la lírica de época arcaica, la historiografía y la retórica de época clásica y, por supuesto, la tradición arquiloquea, apoyan esta afirmación.

El contexto literario del s. III a.C. también pudo influir en la configuración final de este texto: se puso de moda el género de la biografía, generalmente sobre grandes personajes, y los relatos fantásticos, influenciados por las conquistas de Alejandro Magno en Oriente, en torno al cual también giraron multitud de episodios inexplicables y maravillosos. Los autores literarios de época helenística se sentían, además, herederos e imitadores de la literatura griega anterior, solían ser perfeccionistas y utilizaban un lenguaje riguroso con pretensiones de objetividad, pero con cierta finalidad estética y preocupándose por la arquitectura compositiva ${ }^{34}$.

El hecho de que este texto se inscribiera en un soporte imperecedero es un motivo más que justifica el estilo cuidado y elaborado de esta inscripción. Aunque recoja algunos datos de una tradición local oral y popular de siglos atrás, es pertinente destacar que tiene un autor (aunque sea desconocido para nosotros, así como si fueron varios o no), que se trata de una versión de la tradición única y por escrito, y que se le presupone una unidad y organización interna (aunque no se conserve el texto completo de la inscripción).

Tradicionalmente se ha pensado que el autor del texto fue Mnesíepes, pero probablemente este antropónimo también es una ficción más con apariencia de realidad, una creación artística o una reelaboración literaria, pues se trata de un nombre parlante, quizá un pseudónimo: literalmente «el que recuerda las palabras $»^{35}$ (etimológica y mitológicamente ligado a Mnemosine), que

\footnotetext{
${ }^{34}$ Cf. Brioso Sánchez, Literatura helenística: introducción, en López Férez 1988.

35 Este antropónimo solo está documentado en la isla de Paros, y la primera vez que aparece es precisamente en esta inscripción. Cf. Striano 2014.
} 
aúna la poesía, la memoria y el recuerdo de un pasado local, y que además, aparece mencionado sin patronímico, fundamental en el mundo griego. En cualquier caso, hay que tener presente que sólo aparece como receptor de las indicaciones del oráculo y que, después, la personalidad del «redactor»se desdibuja en esa primera persona de plural. Lo que sí parece claro es que el texto presente en la inscripción de Mnesíepes se redactó para ser colocado en las paredes del Archilocheion y que fue redactado en el s. III a.C. siguiendo las modas literarias del momento. Si se tienen en cuenta las marcas presentes en la piedra, quizá podría aventurarse que el texto que sirvió como modelo para grabar esta inscripción era una copia de gran calidad presente en un rollo de papiro. En aquel momento, quizá por motivos socio-políticos, o incluso culturales o económicos, se sintió la necesidad de dejar constancia de un pasado glorioso a la posteridad ${ }^{36}$. Es posible, también, que se solicitara la ayuda de un escritor profesional para elaborar y redactar por encargo este texto, uno de los más importantes de la isla, que seguramente fue revisado y supervisado por la autoridad competente antes de ser grabado en piedra, dada la oficialidad requerida, pues no hay que olvidar que en época helenística muchos poetas, músicos, filósofos y eruditos vagaban de ciudad en ciudad ofreciendo sus servicios. Parecería realista afirmar que en el ambicioso proyecto del Archilocheion confluyeron al menos cuatro posibles motivos que pudieron intervenir en su construcción y en la redacción de este texto: honrar a Arquíloco, reactivar el culto de Apolo, reforzar la identidad local ${ }^{37}$ y, quizá, recuperar esa relevancia cultural de siglos anteriores, dando a conocer dentro y fuera de la isla este monumento, probablemente uno de sus mayores atractivos turísticos ${ }^{38}$.

\footnotetext{
${ }^{36}$ Este acontecimiento en torno a la figura de Arquíloco en Paros no es el único (cf. Lanzillotta 1987, p. 164). En época helenística también en otras islas se sintió la necesidad de recuperar u honrar a otros personajes del pasado, como demuestra, por ejemplo, la inscripción de Demoteles de Andros (IG XI 4, 544). Además, la redacción de este texto probablemente contaba con el apoyo de los ptolomeos, que ejercían su soberanía sobre las Cícladas en ese momento, para quienes tendría también una gran utilidad propagandística (Ornaghi 2009, pp. 271-273).

${ }^{37}$ El s. III a.C. está marcado por continuos enfrentamientos bélicos entre los distintos reinos helenísticos, y las islas habían perdido ya toda su autonomía.

${ }^{38}$ Paros recibía, además, muchos intercambios culturales y económicos procedentes del Pireo y quizá este fuera otro de los motivos para redactar la inscripción en ático (ático-koiné).
} 


\section{BIBLIOGRAFÍA}

Baldassarra, D. 2010: «Le liste cultuali della Grecia nord-occidentale: tipologie, protagonisti e fenomenologia rituale» en Antonetti, C. (ed.), Lo Spazio Ionico e Le Comunità Della Grecia Nord-occidentale. Territorio, Società, Istituzioni (Atti Del Convegno Internazionale, Venezia 7-9 Gennaio 2010). Pisa, pp. 341-371.

Carrizo, S. E. 2011: «Legitimación religiosa de la poética de Arquíloco. La inscripción de Mnesíepes», Belo Horizonte VII, pp. 117-151.

Cassio, A. C. 2008: Storia delle lingue letterarie greche, Florencia.

Clay, D. 2004: Archilochos Heros: The Cult of Poets in the Greek Polis, Washington D.C.

Eidinow, E. 2007: Oracles, Curses, and Risk Among the Ancient Greeks, Nueva York.

Fontenrose, J. E. 1978: The Delphic Oracle: its responses and operations, with a catalogue of response, Berkeley, Los Ángeles, Londres.

Gerber, D. E. 1999: Greek iambic poetry: from the seventh to the fifth centuries BC, Loeb Classical Library, Cambridge, Londres.

Giannisi, P. 2004: «The cows and the poet in ancient Greece» en PECUS. Man and animal in antiquity. Proceedings of the Conference at the Swedish Institute in Rome, September 9-12, 2002, Roma, pp. 125-128.

Guarducci, M. 1967-1978: Epigrafia greca, Roma.

Hansen, M. H. y Nielsen, T. H. 2004: An Inventory of Archaic and Classical Poleis, Nueva York.

Johnson, W. A. 1994: «The function of the Paragraphus in Greek Literary Prose». ZPE 100, pp. 65-68.

Kearns, E. 1992: «Between god and man: status and function of heroes and their sanctuaries» en Schachter, A. (ed.), Le Sanctuaire Grec. Génova, pp. 65-99.

Kenyon, M. A .F. G. 1970: The palaeography of greek papyri, Chicago.

Lanzillotta, E. 1987: Paro, dall' età arcaica all' età ellenistica, Roma.

Lhôte, E. 2006: Les lamelles oraculaires de Dodone, Génova.

López-Eire, A. 1993: «De l'Attique à la koiné» en Brixhe, C., La Koiné Grecque Antique I, Nancy, pp. 41-57.

López Férez, J. A. (ed.) 1988: Historia de la literatura griega, Madrid.

Méndez Dosuna, J. 1985: Los dialectos dorios del noroeste: Gramática y estudio dialectal, Salamanca.

Miralles, C. y Pórtulas, J. 1983: Archilochus and the Iambic Poetry, Roma.

Moralejo Álvarez, J. J. 1971: Gramática de las inscripciones délficas: fonética y morfología hasta el año 200 a.C., Santiago de Compostela.

Ornaghi, M. 2009: La lira, la vacca e le donne insolenti. Contesti di ricezione e promozione della figura e della poesia di Archiloco dall'arcaismo all'ellenismo, Alejandría. 
Privitera, G. A. 1966: «Archiloco e le divinità dell'Archilocheion», Rivista di Filologia e di Istruzione Classica 94, pp. 5-25.

Striano, A. 2012: «Un documento literario rodio: la Crónica del templo de Lindo» en Cabedo Nebot, A. Infante Ríos, P. (eds.), Lingüística XL. El Lingüista Del Siglo XXI. SeL Ediciones, Madrid, pp. 247-251.

Striano, A. 2014: «Aspectos del comportamiento lingüístico de los nombres propios: el ejemplo del griego antiguo» en Martínez Fernández, A., Ortega Villaro, B., Velasco López, H. y Zamora Salamanca, H. (eds.), Ágalma, ofrenda desde la Filología Clásica a Manuel García Teijeiro, Valladolid, pp. 303-311.

Suárez de la Torre, E. 2002: Yambógrafos griegos, Biblioteca Clásica Gredos, Madrid.

Tarditi, G. 1968: Archilochus, Roma.

Thompson, S. 1955: Motif-index of folk-literature: a classification of narrative elements in folktales, ballads, myths, fables, mediaeval romances, exempla, fabliaux, jest-books and local legends, Bloomington.

Thompson, S. 1972: El cuento folklórico. Traducción de Lemmo, A., Universidad Central de Venezuela.

Threatte, L. 1980: The Grammar of Attic Inscriptions, Berlín.

Turner, E. G. 1971: Greek manuscripts of the ancient world, Oxford.

Uther, H. y J. 2004: The types of international folktales: a classification and bibliography, based on the system of Antti Aarne and Stith Thompson, Helsinki.

Williams, F. 1994: "Archilochus and the Eunuch: the Persistence of a Narrative Pattern», Classics Ireland 1, pp. 96-112. 